\section{WHAT IS ALREADY KNOWN ON THIS TOPIC}

Parents of babies in a neonatal intensive care unit have problems recalling information No randomised controlled trials have assessed the effects of providing parents with tapes of their conversations with neonatologists

\section{WHAT THIS STUDY ADDS}

Providing mothers of babies in neonatal intensive care units with tapes of conversations with neonatologists improves their recall of information

The tapes did not affect the mothers' wellbeing or satisfaction with the neonatologist

1 Butt HR. A method for better physician-patient communication. Ann Intern Med 1977:86:478-80.

2 Scott JT, Harmsen M, Prictor MJ, Entwistle VA, Sowden AJ, Watt I. Recordings or summaries of conversations for people with cancer. Cochrane Database Syst Rev 2003;(2):CD001539.

3 Tattersall MH, Butow PN. Conversation audio tapes: an underused cancer patient information aid and clinical research tool. Lancet Oncol 2002;3:431-7.

4 Ong LM, Visser MR, Lammes FB, van Der Velden J, Kuenen BC, de Haes JC. Effect of providing cancer patients with the audiotaped initial conversation on satisfaction, recall, and quality of life: a randomized, double-blind study. J Clin Oncol 2000;18:3052-60.

5 Hogbin B, Jenkins VA, Parkin AJ. Remembering 'bad news' consultations: an evaluation of tape-recorded consultations. PsychoOncology 1992;1:147-54.

6 McHugh P, Lewis S, Ford S, Newlands E, Rustin G, Coombes C, et al. The efficacy of audiotapes in promoting psychological well-being in cancer patients: a randomised, controlled trial. Brit/ Cancer 1995;71:388-92.

7 Koh THHG, Budge D, Butow P, Renison B, Woodgate P. Audio recordings of conversations with doctors for parents of critically sick babies. Cochrane Database Syst Rev 2005;(1):CD004502.

8 Spielberger CD, Gorsuch RL, Lushene RE. Manual for the state-trait anxiety inventory. Palo Alto, CA: Consulting Psychologists Press, 1970.

9 Development of the 10-item Edinburgh postnatal depression scale. $B$ I Psychiatry 1987:150:782-6.

10 Goldberg DP, HillierVF. A scaled version of the general health questionnaire. Psychol Med 1979;9:139-45.

11 Abidin RR. Parenting stress index-manual. Charlottesville VA: Pediatric Psychology Press, 1990.

12 Brown R, Dunn S, Butow P. Meeting patient expectations in the cancer conversation. Ann Oncol 1997;8:877-82.

13 Tattersall MH, Butow PN, Griffin AM, Dunn SM. The take-home message: patients prefer conversation audiotapes to summary letters. J Clin Oncol 1994;12:1305-11.

14 Cassileth BR, Zupkis RV, Sutton-Smith K, March V. Information and participation preferences among cancer patients. Ann Intern Med 1980;92:832-6.

15 Buunk BP. Relationship interaction satisfaction scale. In: Touliatos J, Perlmutter BF, Straus MA, eds. Handbook offamily measurement techniques. Newbury Park, CA: Sage, 1990:106-7.

16 Sarason I, Sarason B, Shearin E, Pierce G. A brief measure of social support: practical and theoretical implications. J Soc Pers Relat 1987;4:497-510.

17 Anon. CRIB (clinical risk index for babies), mortality, and impairment after neonatal intensive care. Scottish Neonatal Consultants' Collaborative Study Group and the International Neonatal Network. Lancet 1995;345:1020-2.

18 Hagan R, Evans SF, Pope S. Preventing postnatal depression in mothers of very preterm infants: a randomised controlled trial. Brit) Obstetr Gynaecol 2004;111:641-7.

19 Snowdon C, Garcia J, Elbourne D. Making sense of randomization; responses of parents of critically ill babies to random allocation of treatment in a clinical trial. Soc Sci Med 1997;45:1337-55.

Accepted: 13 October 2006
National Primary Care Research and Development Centre, Centre for Health Economics, University of York, York Y010 5DD

2University of Plymouth, Peninsula Allied Health Centre, College of St Mark and St John, Plymouth PL6 8BH

${ }^{3}$ Manchester Business School, University of Manchester

Manchester M156PB

${ }^{4}$ National Primary Care Research and

Development Centre, University of

Manchester, Manchester M139PL

${ }^{5}$ Sheffield Institute for Studies of

Ageing, University of Sheffield,

Barnsley Hospital NHS Foundation

Trust, Barnsley S752EP

Correspondence to: $\mathrm{M}$ Roland

m.roland@manchester.ac.uk

BMJ 2007;334:31-4

doi=10.1136/bmj.390120.413310.55

This article is the abridged version of a paper that was published on bmj.com on 15 November 2006. Cite this version as $B M / 15$ November 2006, doi: $10.1136 /$ bmj.39020.413310.55 (abridged text, in print: $B M / 2007 ; 334: 31-4$ )

\title{
Impact of case management (Evercare) on frail elderly patients: controlled before and after analysis of quantitative outcome data
}

\author{
Hugh Gravelle, ${ }^{1}$ Mark Dusheiko, ${ }^{1}$ Rod Sheaff, ${ }^{2}$ Penny Sargent, ${ }^{3}$ Ruth Boaden, ${ }^{3}$ Susan Pickard, ${ }^{4}$ Stuart Parker, ${ }^{5}$ \\ Martin Roland ${ }^{4}$
}

\section{ABSTRACT}

Objectives To determine the impact on outcomes in patients of the Evercare approach to case management of elderly people.

Design Practice level before and after analysis of hospital admissions data with control group.

Setting Nine primary care trusts in England that, in 2003-5, piloted case management of elderly people selected as being at high risk of emergency admission.

Main outcome measures Rates of emergency admission, emergency bed days, and mortality from April 2001 to March 2005 in 62 Evercare practices and 6960-7695 control practices in England (depending on the analysis being carried out).

Results The intervention had no significant effect on rates of emergency admission (increase 16.5\%, 95\% confidence interval $-5.7 \%$ to $38.7 \%$ ), emergency bed days (increase $19.0 \%,-5.3 \%$ to $43.2 \%$ ), and mortality (increase $34.4 \%$, $-1.7 \%$ to $70.3 \%$ ) for a high risk population aged $>65$ with a history of two or more emergency admissions in the preceding 13 months. For the general population aged $\geq 65$ effects on the rates of emergency admission (increase $2.5 \%$, $-2.1 \%$ to $7.0 \%$ ), emergency bed days (decrease $-4.9 \%$, $-10.8 \%$ to $1.0 \%$ ), and mortality (increase $5.5 \%,-3.5 \%$ to
$14.5 \%)$ were also non-significant.

Conclusions Case management of frail elderly people introduced an additional range of services into primary care without an associated reduction in hospital admissions. This may have been because of identification of additional cases. Employment of community matrons is now a key feature of case management policy in the NHS in England. Without more radical system redesign this policy is unlikely to reduce hospital admissions.

\section{INTRODUCTION}

Case management of frail elderly people was recently introduced into the NHS and subsequently became a key component of the national community matron policy. ${ }^{1}$ Case management aims to improve outcomes in patients and, in particular, to reduce unplanned hospital admission.

Systematic reviews of home based support for older people have drawn mixed conclusions from no overall impact on hospital admission ${ }^{2}$ to reduced admission rates and costs, dependent on the system of care. ${ }^{3}$ Two further reviews concluded that there is limited evidence that case management of elderly people can reduce use of health services, but both suggest that the results from 
Table 1 | Effect of intervention for the high risk population (aged $\geq 65$, two emergency admissions in preceding 13 months) in 62 intervention practices and at least 6960 control practices. Effects shown with $95 \%$ confidence intervals

\begin{tabular}{|c|c|c|c|c|c|c|}
\hline \multirow{2}{*}{ Outcome } & \multicolumn{3}{|c|}{ Regression based estimates* } & \multicolumn{3}{|c|}{ Propensity score matched estimatest } \\
\hline & Estimated effect $¥ /$ person/year & Percentage effect§ (\%) & Pvaluef & Estimated effect $¥ /$ person/year & Percentage effect§ (\%) & Pvalueף \\
\hline Emergency admissions & $0.10(-0.03$ to 0.22$)$ & $16.5(-5.7$ to 38.7$)$ & 0.14 & $0.09(-0.03$ to 0.22$)$ & $16.3(-6.0$ to 38.5$)$ & 0.15 \\
\hline Emergency bed days & $1.3(-0.4$ to 3.0$)$ & $19.0(-5.3$ to 43.2$)$ & 0.13 & $1.08(-0.61$ to 2.77$)$ & $15.6(-8.7$ to 39.9$)$ & 0.21 \\
\hline HES mortality & 0.03 (0.0 to 0.07$)$ & $34.3(-1.7$ to 70.3$)$ & 0.06 & 0.03 (0.0 to 0.07$)$ & $34.9(-1.1$ to 71.1$)$ & 0.06 \\
\hline
\end{tabular}

*From fixed effect panel regression, allowing for clustering within practices and heteroscedasticity

tFrom matching by propensity score and stratification.

¥Estimated change (period 6 minus period 3) in mean outcome for intervention minus control. Period 3=six months from October 2002 ; period $6=$ six months from October 2004.

$\S 100^{*}$ estimated effect/mean outcome rate for Evercare practices in period 3.

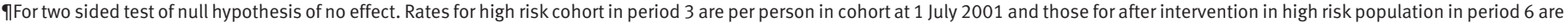
per person in cohort at 1 July 2003.

Table 2 | Effect of intervention for the general practice population aged $\geq 65$ in 64 intervention practices and at least 6938 control practices. Effects shown with $95 \%$ confidence intervalsz

\begin{tabular}{|c|c|c|c|c|c|c|}
\hline \multirow{2}{*}{ Outcome } & \multicolumn{3}{|c|}{ Regression based estimates* } & \multicolumn{3}{|c|}{ Propensity score matched estimatest } \\
\hline & Estimated effect $¥ /$ person/year & Percentage effect§ (\%) & Pvalueף & Estimated effect/person/year & Percentage effect§ (\%) & Pvalueף \\
\hline Emergency admissions & $0.01(-0.01$ to 0.02$)$ & $2.5(-2.1$ to 7.0$)$ & 0.29 & $0.005(-0.005$ to 0.016$)$ & $2.3(-2.2$ to 6.7$)$ & 0.31 \\
\hline Emergency bed days ${ }^{\star \star}$ & $-0.15(-0.33$ to 0.03$)$ & $-4.9(-10.8$ to 1.0$)$ & 0.10 & $-0.17(-0.35$ to 0.002$)$ & $-5.7(-11.4$ to 0.1$)$ & 0.05 \\
\hline HES mortality & $0.003(-0.002$ to 0.007$)$ & $5.5(-3.5$ to 14.5$)$ & 0.23 & $0.003(-0.001$ to 0.007 & $5.7(4.9$ to 14.2$)$ & 0.19 \\
\hline
\end{tabular}

individual studies cannot readily be generalised to different healthcare settings. ${ }^{45}$

In England case management was introduced by UnitedHealth Europe as pilots of the Evercare model of case management in April 2003. Evercare sites initially selected patients on the basis of age $(\geq 65)$ and a history of emergency admissions. Advanced practice nurses agreed individualised care plans with the patient, the general practitioner, and other staff, and patients were monitored. The benefits reported included altering medication to avoid adverse reactions, coordinating care to reduce fragmentation among services, and arranging access to community based services. The nurses judged that the intervention improved patients' functional status and quality of life and avoided hospital admissions. ${ }^{6}$

We carried out a quantitative and qualitative evaluation of the Evercare pilots. The qualitative part included interviews with staff from United Health and primary care trusts, general practitioners, patients, carers, and advanced practice nurses, and the findings from these are reported elsewhere. ${ }^{78}$ In this paper we report on the effect of Evercare pilots on hospital admissions, bed days, and mortality.

\section{METHODS}

Study population and outcomes-The study period ran from 1 July 2003 to 31 March 2005. The intervention practices $(n=64)$ were those that had patients enrolled in Evercare at any time between 1 July 2003 and 31 March 2005. We took as the control group all other practices in England ( $\mathrm{n}=6960-7695$, depending on the analysis). We could not track individual Evercare patients' use of hospital and NHS services so we measured outcomes at practice level. The outcomes were practice rates of emergency admissions, emergency bed days, and mortality estimated from hospital episode statistics (HES). We measured outcome rates for two populations: a high risk cohort of patients aged $\geq 65$ with two or more emergency admissions in the preceding 13 months and all patients aged $\geq 65$.

Analysis-We used a design that compared the change in outcomes in the Evercare practices before and during the intervention with the change in outcomes in the control practices before and during the intervention. ${ }^{9}$ This design removes the effect of baseline differences between the groups. We defined three periods before the intervention (period 1: July 2001 to March 2002; period 2: April 2002 to September 2002; period 3: October 2002 to March 2003) and three during the intervention (period 4: July 2003 to March 2004; period 5: April 2004 to September 2004; period 6: October 2004 to March 2005). We then compared period 4 against period 1, 5 against 2, and 6 against 3 to remove possible seasonal effects. We regressed the outcome rate on indicators to denote the period being analysed, an indicator for the intervention group, and interactions between the intervention group indicator and the period indicators. We also controlled for differences between Evercare and control practices using propensity score matching. ${ }^{10} 11$ This method allowed us to compare Evercare practices with control practices that were similar in terms of the factors that influenced the probability of a practice being enrolled in Evercare.

\section{RESULTS}

At baseline, intervention practices had significantly higher rates of admission and use of emergency bed days and faster growth rates in admissions for the general population aged $\geq 65$ (see bmj.com). Although 
intervention practices had more high risk patients, the outcomes for their high risk populations at baseline were similar to those in the control practices. Intervention practices also served populations with more health deprivation.

The results from the multiple regression models (see table A1 on bmj.com) showed that practices with a larger total list, with a higher health deprivation score, and with a higher growth rate in admissions were more likely to be in the intervention group. We therefore included these variables in the matched control analyses.

Tables 1 and 2 show the effect of the intervention as the estimated change in outcome between the last period before the intervention (period 3) and the last period during the intervention (period 6) for the Evercare practices minus the estimated change between period 3 and period 6 for the control practices. Table 1 shows the effects of the intervention in high risk patients (aged $\geq 65$ and two admissions in the previous 13 months). The rates of admission and bed days and mortality were all higher in the intervention group, though none of the effects was significant at the $5 \%$ level. Table 2 presents the results for the general population aged $\geq 65$, showing that the rate of admissions and mortality were higher in Evercare practices and the bed day rate reduced. None of these differences was significant.

The results were the same when we used patient years at risk as the denominator for the analysis of the high risk group (see table A2 on bmj.com) and when we included a measure of practice population exposure or the rate denominator in the regression models in an attempt to allow for errors in population measurement.

The figure shows differences in admission rates in the general population aged $\geq 65$.

\section{DISCUSSION}

The Evercare pilots represent the first widespread implementation of case management in the NHS. Our qualitative evidence suggests that access to case management added a frequency of contact, regular monitoring, psychosocial support, and a range of referral options that had not previously been provided to frail elderly people. In this quantitative analysis, however, we found that case management had no significant impact on rates of emergency admission, bed days, or mortality in high risk cohorts. These results are consist-

\section{WHAT IS ALREADY KNOWN ON THIS TOPIC}

Case management of frail elderly people can affect outcomes, depending on the context in which it is introduced

The NHS introduced case management using the Evercare approach provided by UnitedHealth Europe in nine trusts in England

Employment of community matrons is now a key feature of case management policy in the NHS in England

\section{WHAT THIS STUDY ADDS}

Evercare's approach to case management in the NHS in England did not reduce emergency admissions, emergency bed days, or mortality

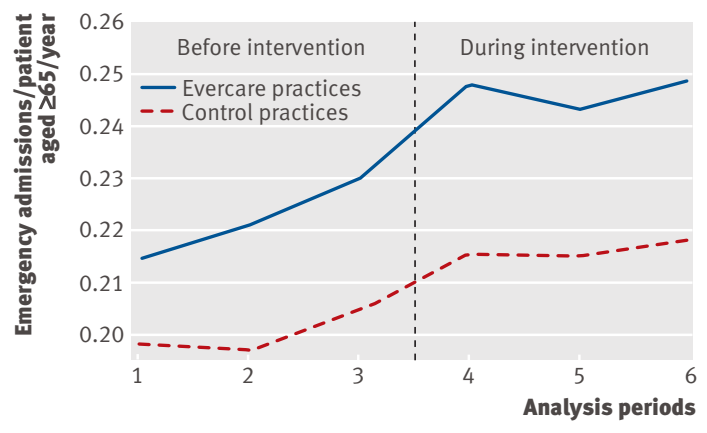

Emergency admission rates for general population aged $\geq 65$ in Evercare and control practices. Before intervention: period 1: 1 July 2001 to 31 March 2002; period 2: 1 April 2002 to 30 September 2002; period 3: 1 October 2002 to 31 March 2003). During intervention: period 4: 1 July 2003 to 31 March 2004; period 5: 1 April 2004 to 30 September 2004; period 6: 1 October 2004 to 31 March 2005

ent with those from a small case-control study from the limited evaluation at patient level published by UnitedHealth Europe. ${ }^{6} 12$

\section{Caveats on interpretation}

Our criterion for defining the high risk group was based on data from hospital episode statistics and does not correspond exactly with the criteria used to select Evercare patients. However, there is probably considerable overlap between our high risk group and Evercare patients as at least $69 \%$ of Evercare patients had two or more emergency admissions in the previous 13 months. ${ }^{6}$ The small number of intervention practices meant that the study had relatively low power to detect changes in outcomes.

We did not collect data on a range of other important outcomes, especially on any direct measures of the health of the target population. The intervention and control practices had different admission rates at baseline, though our analyses controlled for these.

Our estimate of mortality failed to count some deaths outside hospital, and we probably underestimated mortality less in practices with higher rates of admission as more of their patients who die will have been in hospital recently and hence have their death recorded by hospital episode statistics.

Case management of frail elderly people in the NHS introduced an extra range of services to primary care without reducing hospital admissions. Although lessons have been learnt from these initial pilots-for example, better methods of identifying high risk groups ${ }^{13}$-we predict the same outcome from the newly introduced community matron policy, which is based on the same principles. Community matrons are likely to be popular with patients and increase access to care, but they are unlikely to reduce hospital admissions unless there is also a more radical system redesign.

Contributors: See bmj.com.

Funding: Department of Health grant to the National Primary Care Research and Development Centre.

Competing interests: None declared.

Ethical approval: Thames Valley multi-centre ethics committee. 
1 Department of Health. Supporting people with long term conditions: liberating the talents of nurses who care for people with long term conditions. London: Department of Health, 2005.

2 Elkan R, Kendrick D, Dewey M, Hewitt M, Robinson J, Blair M, et al. Effectiveness of home based support for older people: systematic review and meta-analysis. $B M / 2001 ; 323: 719-25$.

3 Johri M, Beland F, Bergman H. International experiments in integrated care for the elderly: a synthesis of the evidence. Int J Geriatr Psychiatry 2003;18:222-35.

4 Hutt R, Rosen R, McCauley J. Case managing long term conditions. London: King's Fund, 2004. www.kingsfund.org.uk/resources/ publications/case managing.html.

5 Singh D. Transforming chronic care: evidence about improving care for people with long term conditions. Birmingham: Health Services Management Centre, University of Birmingham, 2005. www.hsmc. bham.ac.uk/news/Improving\%20Care-Apr06.pdf.

6 UnitedHealth Europe. Assessment of the Evercare programme in England 2003-2004.www.cat.csip.org.uk/_library/evercare\%20fin al\%20report.pdf.

7 Boaden R, Dusheiko M, Gravelle H, Parker S, Pickard S, Roland M, et al. Evaluation of Evercare: final report. Manchester: National Primary Care Research and Development Centre, University of Manchester, 2006. www.npcrdc.ac.uk/pr33.

8 Boaden R, Dusheiko M, Gravelle H, Parker S, Pickard S, Roland M, et al. Evaluation of Evercare: executive summary. Manchester: National Primary Care Research and Development Centre, University of Manchester, 2006. www.npcrdc.ac.uk/es42.

9 Wooldridge JM. Econometric analysis of cross section and panel data. Cambridge, MA: MIT Press, 2002.

10 Rubin DB. Estimating causal effects for large data sets using propensity scores. Ann Intern Med 1997;127:757-63.

11 Becker SO, Ichino A. Estimation of average treatment effects based on propensity scores. Stata Journal 2002;2:358-77.

12 UnitedHealth Group. Implementing the Evercare programme. Interim report. London: UHG, 2004. www.networks.nhs.uk/40.php\#Evercar.

13 Billings J, Dixon J, Mijanovich T, Wennberg D. Case finding for patients at risk of readmisison to hospital: development of algorithm to identify high risk patients. BMJ 2006;333:327-32.

Accepted: 24 October 2006

\section{BMJ UPDATES}

\section{Long term hormone replacement therapy with estradiol alone is linked to breast cancer}

\section{Research question}

What are the risks of breast cancer associated with different types of oestrogen only hormone replacement therapy?

\section{Answer}

Women who use oral or transdermal estradiol for more than five years have a higher risk of breast cancer than the general population.

\section{Why did the authors do the study?}

The evidence linking oestrogen only hormone replacement therapy to breast cancer is mixed. These authors wanted to find out if the risk varied with the type of oestrogen, the dose, or the route of administration. They focused on estradiol, the oestrogen most commonly used by women in Europe.

\section{What did they do?}

They linked data from a Finnish register containing records of all reimbursements for oestrogen only hormone replacement therapy, with data from the Finnish cancer registry, which is thought to be almost $100 \%$ complete. Most of the reimbursements were for estradiol pills, patches, or gels. The few women prescribed conjugated equine oestrogens were excluded from the analysis. The authors looked for associations between breast cancer incidence and hormone use by calculating standardised incidence ratios-the ratio of observed to expected cases of breast cancer among women using systemic estradiol (oral or transdermal), oral estriol, or vaginal oestrogen creams. They did separate analyses for short term (up to five years) and long term (five years or more) use. The final cohort included 110984 postmenopausal women aged over 50 who had used oestrogen alone for more than six months. All the women had had a hysterectomy.

\section{What did they find?}

Women who took estradiol orally or transdermally for less than five years were no more likely to get breast cancer than women of a similar age in the general Finnish population (standardised incidence ratio 0.93 (95\% $\mathrm{Cl} 0.8$ to 1.04$)$ ), but longer use of systemic therapy was associated with a significant rise in breast cancer incidence (ratio 1.44 (1.29 to 1.59)). Vaginal oestrogens and oral estriol seemed safe, even when used for more than five years.

The risk associated with long term use of systemic estradiol didn't vary significantly with the dose. Long term use was associated with both lobular and ductal cancers, and with both early and later stage disease.

\section{What does it mean?}

These data suggest a link between breast cancer and long term treatment with oral or transdermal estradiol in postmenopausal Finnish women. It's possible that the hormone encourages the growth of breast cancers directly, but it's also possible that confounding factors such as body weight, age at the birth of the first child, and parity were at least partly responsible for the inflated risk. The authors were unable to account for any of these factors in their analysis, so we can't say for certain that the observed association was causal. Detection bias could also be relevant here. Women taking hormone replacement therapy may be more likely than other women to have breast examinations and mammograms.

Lyytinen et al. Breast cancer risk in postmenopausal women using estrogen-only therapy Obstetrics and Gynecology 2006;108:1354-60.

This summarises a paper that has been selected by bmjupdates. To register for bmjupdates (free email about high quality new papers in your favourite subjects) go to http://bmjupdates.com/ 